\title{
O engessamento de determinados gêneros discursivos reduz, mas não é capaz de eliminar as marcas deixadas pelo sujeito
}

\author{
Sarah Temponi Soares Soares ${ }^{*}$
}

\begin{abstract}
Resumo
A escrita de determinados gêneros discursivos enfrenta uma condição denominada "engessamento". Essa problemática tem sido apontada, uma vez que as condições de escrita, exigências, normas e imposições que esta sofre produzem certa cristalização do gênero, exigindo por parte de quem escreve inserir sua produção nos moldes e formas pré-estabelecidos. A consequência dessa condição de escrita "controlada" seria a perda identitária do sujeito. Este artigo busca, a partir da análise de corpus dos dois gêneros considerados "engessados", defender as seguintes teses: a) O engessamento de determinados gêneros discursivos reduz, mas não é capaz de eliminar as marcas deixadas pelo sujeito. b) "Quanto melhor dominamos os gêneros, mais livremente os empregamos." (Bakhtin, 2003, p. 285)

Palavras-chave: Gêneros discursivos. Sujeito. Artigo científico. Redação. ENEM.
\end{abstract}

* Pontifícia Universidade Católica de Minas Gerais (PUC Minas). Mestranda do Programa de Pós-graduação em Letras da PUC Minas. Especialista em Revisão de Textos pela PUC Minas. Bolsista CNPq. ORCID: http://www.orcid.org/0000-0002-0313-8510. 


\title{
L'immobilisation de certains genres discursifs réduit, mais ne parvient pas à éliminer les marques laissées par le sujet
}

\author{
Sarah Temponi Soares Soares
}

\begin{abstract}
Resumé
L'écriture de certains genres discursifs est confrontée à une condition appelée "plâtré". Cette question a été signalée, car les conditions décriture, les exigences, les normes et les impositions quelle subit produisent une certaine cristallisation de l'écriture, exigeant de la part de ceux qui écrivent d'insérer leur production dans les moules et les formes préétablis. La conséquence de cette condition décriture "contrôlée" serait la perte d'identité du sujet. Cet article cherche, à partir de l'analyse de deux genres considérés "en plâtre", à défendre les thèses suivantes : a) Le plâtrage de certains genres discursifs réduit, mais n’est pas capable déliminer les marques laissés par le sujet. b) «Mieux nous maitrisons les genres, plus nous les employons librement.» (Bakhtin, 2003, p. 285)
\end{abstract}

Mots-clés: Genres discursifs. Sujet. Article scientifique. Rédaction. ENEM. 


\section{Introdução}

$\mathrm{O}$ atual modelo de escrita da redação do Enem exemplifica uma problemática questão: o engessamento desse gênero discursivo seria responsável por uma perda identitária do sujeito. Assim como na redação do Enem, vemos, na escrita de artigo científico, a ocorrência de exigências, normas, imposições e condições de escrita que resultam em pouca mobilidade por parte de quem escreve. Na posição de aluna do mestrado em Letras e de professora de redação de participantes do Enem, gostaria de defender as seguintes teses:

a) O engessamento de determinados gêneros discursivos reduz, mas não é capaz de eliminar as marcas deixadas pelo sujeito.

b) "Quanto melhor dominamos os gêneros, mais livremente os empregamos." (Bakhtin, 2003, p 285)

Assim, a proposta de caminho para este artigo é, inicialmente, estabelecer um diálogo entre estes dois gêneros discursivos - redação do Enem e artigo científico - enquanto enunciados que se dão em situação comunicativa de pouca flexibilidade, na qual se pressupõe uma tentativa de silenciamento do sujeito. Apesar de bem distintos, é possível verificar relações entre os gêneros, em vista das cristalizações que engendram tais produções.

Além disso, pretende-se analisar essas tentativas de apagamento do sujeito e verificar de que maneira elas constroem uma ilusão de anonimato, revelando as marcas de sujeito deixadas ao longo da escrita.

Por fim, busca-se demonstrar como o domínio dos gêneros em estudo é capaz de possibilitar "liberdade" de escrita.

\section{Da noção de gênero}

Inicialmente, é relevante esclarecer alguns conceitos que serão utilizados. A noção de gênero aqui assumida é a idealizada por Bakhtin (2011, p. 274). De acordo com o filósofo, 
os gêneros constituem formas relativamente estáveis de enunciados, disponíveis na cultura, caracterizados por três elementos: conteúdo temático, estilo e construção composicional. As intenções comunicativas, como parte das condições de produção dos discursos, geram usos sociais que determinam os gêneros que darão forma aos textos.

A visão de gênero, de acordo com Bakhtin, pode ser resumida nas seguintes ideias:

a) Cada esfera de troca social elabora tipos relativamente estáveis de enunciados: os gêneros;

b) Três elementos os caracterizam: conteúdo temático, estilo e construção composicional;

c) A escolha de um gênero se determina pela esfera, as necessidades da temática, o conjunto de participantes e a vontade enunciativa ou intenção do locutor.

Percebe-se, nessa concepção de gênero, a estabilidade da forma como uma característica própria dos gêneros discursivos. Essa qualidade apresenta-se de maneira mais ou menos rígida a depender do gênero em questão, em vista das condições de produção e dos usos sociais que fazemos dos textos. Veremos que, nos gêneros em análise neste artigo, há uma estabilidade de forma bem cristalizada, o que se aponta como um potencial defeito/problema, haja vista que a pouca possibilidade de alternância pode ser compreendida como uma tentativa de controle da escrita. Contudo, sabemos que essa realidade é própria da organização da nossa sociedade e do uso social que se faz dos gêneros. Nesse sentido, sempre haverá tentativa de controle da produção escrita, principalmente quando se trata de gêneros que circulam em um contexto comunicativo de validação social. Isso ocorre porque o gênero nasce em um contexto social e a sua função é atender a esse propósito comunicativo que o originou. Assim, as suas características refletem as visões sociais que existem acerca daquela condição de produção e finalidade comunicativa. É muito árdua, apesar de valiosa, a luta contra as tentativas de controle. Há meios, porém, de ser "livre" apesar das imposições.

Ainda, segundo Bakhtin (2011, p. 302), "se não existissem os gêneros do discurso e se não os dominássemos, se tivéssemos de criá-los 
pela primeira vez no processo da fala, se tivéssemos de construir cada um de nossos enunciados, a comunicação verbal seria quase impossível".

Nesse viés, é importante que consideremos que, na imensa maioria dos casos, não somos nós que criamos os gêneros a partir das necessidades de uso. Nós nos apropriamos dos gêneros que nos são dados, assim eles nos servem como meio, como instrumento valioso de comunicação verbal. No entanto, os gêneros estão sujeitos a modificações em virtude do momento social, ou seja, do contexto histórico no qual se inserem. Assim, a existência de novos gêneros está ligada ao surgimento constante e necessário de novas esferas de atividade humana, cujas finalidades discursivas requerem especificidades. Desse modo, os gêneros discursivos são práticas textuais vinculadas à vida social, entidades sociodiscursivas e formas de ação social que fazem parte da situação comunicativa. Surgem lado a lado às necessidades interacionais.

Compreender, portanto, como determinados gêneros se constituem em situações comunicativas que promovem engessamento ou redução do sujeito é um dos objetivos deste artigo. Não se busca aqui, no entanto, desmerecer a relevância social de tais gêneros. Ao contrário, o que se defende é o próprio gênero enquanto instrumento de valor para atividade humana.

O que pretendemos mostrar aqui é como os gêneros se constituem a partir de determinadas práticas sociais. Ele nasce de uma necessidade humana em um determinado espaço sócio-histórico-cultural. A partir dessa concepção, podemos pensar que tanto os textos quanto os gêneros são resultados de experiências e, portanto, de atividades humanas. Eles possuem uma série de princípios e parâmetros que se ancoram em um determinado contexto situacional, em uma estrutura e em regras do sistema linguístico.

\section{Da noção de sujeito}

A noção de sujeito aqui empregada é a compreendida e apresentada por Volóchinov (2017) em sua obra Marxismo e Filosofia da Linguagem. Nessa concepção, o sujeito, cuja existência se dá através da linguagem, é 
visto como atravessado pelas marcas sociais e históricas que o constituem. Fruto de interações, esse sujeito é sempre ideológico, nunca neutro. Isso porque toda ação humana está impregnada de um universo de valores dos quais o sujeito não é capaz de se desvincular. Assim, toda ação é também uma atitude de posicionamento que o indivíduo assume a todo tempo frente aos valores ideológicos.

Sendo um sujeito social, ao entrar em contato com outros enunciados, ele interage com os discursos em uma atitude responsiva, na qual concorda ou discorda, complementa e se constrói na interação. Cada indivíduo é único, porém cada um de nós é produto das relações que estabelecemos com o outro. Nós precisamos dessas relações para nos inserirmos no mundo, pois é delas que nos constituímos. Não há, nessa perspectiva, a possibilidade de se falar então em consciência individual, uma vez que toda consciência é coletiva, pois dela ecoam muitas vozes que podemos reafirmar, confrontar ou, até mesmo, tentar ignorar.

A concepção de um sujeito atravessado e sempre social parece contrapor-se à noção de indivíduo único e subjetivo, mas não o faz. É justamente o atravessamento que faz de cada indivíduo único. Cada um de nós vamos ser construídos e constituídos de uma travessia que nos é particular.

Ainda nessa perspectiva, o sujeito não pode ser visto como separado da linguagem, uma vez que é por meio dela que ele se inscreve no mundo em uma posição responsiva que é feita da/na linguagem. Inscrever-se no mundo implica estar no campo de ação da linguagem, o que significa ser convidado a pensar o mundo e, portanto, todo pensamento, todo ato implica essa atitude responsiva do sujeito. Essa percepção está alinhada à ideia de que o sujeito produz enunciados que não são nunca terminados e que estão sempre ocorrendo de forma responsiva a outros ditos, já que nenhum de nós é um Adão mito de Bakhtin. Assim, todo sujeito produz enunciados que se inserem em um elo inseparável de outros enunciados.

Nessa atitude responsiva, inclui-se não apenas a resposta, o ato de colocar-se em relação ao mundo, ao outro, mas também uma responsabilidade, isto é, inclui uma assinatura que é inerente ao ato da linguagem e revela uma posição do sujeito. Desse modo, se cada sujeito é oriundo de atravessamentos próprios das suas experiências sociais, é ilusão 
pensar na ideia de possibilidade de apagamento das marcas do sujeito na linguagem.

Assim, concebe-se a linguagem em sua essência, em sua capacidade de atravessar o sujeito e, ao mesmo tempo, possibilitar que o sujeito atravesse o mundo, dando-lhe existência. E é essa linguagem que possibilita a inserção do sujeito no mundo através de uma ação participativa, determinando as ideologias, as relações socialmente organizadas, que por sua vez são estabelecidas na constituição do sujeito que se coloca no mundo não de forma autônoma, mas atrelado ao fator social.

\section{Redação do Enem}

A redação do Enem é a produção de texto escrita pelos candidatos ao Exame Nacional do Ensino Médio, criado em 1998. Nesse contexto, o estudante é convidado a produzir um texto dissertativo-argumentativo. Essa proposição de escrita trouxe à tona a problemática de que a redação do Enem se enquadraria apenas na categoria de tipologia textual. Isso se tornou uma questão, uma vez que, dentro da categoria dos textos dissertativosargumentativos, cabe uma multiplicidade de gêneros discursivos, tais como carta argumentativa, artigo de opinião, editorial, etc. Sabe-se, contudo, ao longo desses mais de vinte anos de aplicação do exame, que a redação do Enem não se encaixa na concepção de qualquer gênero escrito nos moldes da tipologia dissertativo-argumentativo. O que se espera do candidato é que este escreva dentro de uma situação comunicativa bem específica na qual se determina tema de produção, número de linhas que serão construídas, estrutura, linguagem, destinatário etc. Dessa forma, é evidente, à luz da noção de gênero bakhtiniana, que a redação do Enem é atualmente um gênero discursivo, uma vez que, além de sua estabilidade de forma, o contexto de escrita é bem definido, e o texto existe para uma finalidade social específica que o diferencia dos demais gêneros pertencentes à tipologia dissertativoargumentativo.

A redação do Enem trata-se de uma produção que está atrelada a um ambiente avaliativo. $\mathrm{O}$ texto é endereçado a um corretor de redação. $\mathrm{O}$ sujeito escrevente produz na condição de um candidato anônimo sobre o 
qual se constrói apenas o imaginário de um estudante, jovem, concluinte do Ensino Médio. O texto produzido ali é encomendado, determina-se o tema, o número de linhas que serão escritas, o direcionamento da argumentação - visando à construção de uma proposta de intervenção. De fato, não é um gênero em que se sobressai a criatividade ou a liberdade de quem escreve. É um texto bastante engessado, de forma estável. Porém, esse aspecto um tanto quanto compreendido como falho/problemático do modelo avaliativo foi um dos responsáveis pela criação do gênero redação do Enem. Isso porque os gêneros pertencentes à tipologia dissertativo-argumentativo existem e circulam em situações comunicativas que lhes são próprias. Por exemplo, o artigo de opinião é um gênero que pertence ao contexto jornalístico e possui características bem determinadas, tais como espaço de circulação, leitores, estratégias argumentativas próprias, tais como o uso da ironia. Ele atende a um propósito comunicativo específico. O Enem acontece em outro contexto que é único e particular. Não é possível transferir um gênero para uma outra situação comunicativa sem acabar por mutilá-lo ou distorcê-lo. Quando se pede para que um estudante produza um artigo de opinião em sala de aula ou em um exame de vestibular, esse aluno vai produzir um texto que não pode ser mais considerado um artigo de opinião, haja vista que o contexto de produção não é mais o mesmo e esse contexto social é o que faz o gênero existir como tal. Assim, não seria possível que o Enem propusesse em sua avaliação a construção de um gênero de uso social sem que este precisasse ser relocado ao contexto de escrita/recepção ao qual o Enem pertence.

Desse modo, o Enem acabou por criar um gênero novo, específico para a situação social em que ele é produzido e circula. Sendo assim, há aspectos determinados para sua construção que aparentemente são um problema, pois certamente tornam o texto mais rígido/engessado, mas são esses mesmos aspectos que proporcionam a sua efetividade enquanto gênero que exerce um propósito comunicativo. Além disso, não se pode negar que há uma coerência entre o que é cobrado e a finalidade de se avaliar o candidato buscando o máximo de objetividade, padronização. Isso porque é de conhecimento as condições de correção dos textos, o volume de correções realizadas por cada corretor diariamente e a necessidade de eficiência desse processo avaliativo. Assim, o problema não está no gênero. Ele cumpre o seu papel, ainda que este possa ser questionável. A 
problemática se encontra na falta de esclarecimento e de transparência acerca desse gênero e no pouco ou nenhum domínio que os candidatos têm dele. Sem domínio, os estudantes tornam-se reféns de escritas préconstruídas, arquétipos, que em muito limitam a escrita.

\section{Artigo científico}

O gênero artigo científico é bastante diverso se considerarmos as variadas perspectivas que o engendram. A produção de textos no contexto universitário é um importante objeto de pesquisa, que pode ser produzido para submissão a alguma revista científica, mas também é muito usual como prática avaliativa, presente em atividades e trabalhos acadêmicos, proposta por professores de disciplinas da graduação e da pós-graduação. Em qualquer desses cenários, este gênero é concebido enquanto uma escrita que se realiza nas universidades como um instrumento ou uma ferramenta de afirmação ou verificação da produção de saberes para a formação de alunos-pesquisadores. $\mathrm{O}$ contexto de produção do gênero coloca o sujeito escrevente em condição bastante engessada. Segundo Amorim,

o texto científico se organiza sob a forma de relato: em ausência de interlocução e fora da esfera pessoal. Suas afirmações se enunciam por uma forma não pessoal porque o sujeito que as enuncia e um eu que visa ao lugar de uma não-pessoa. É um locutor que se apresenta para aceder a condição impessoal. Pois se o que ele diz é verdadeiro, se sua argumentação se sustenta, qualquer pessoa poderá afirmá-lo. Que ele se enuncie com o pronome nós ou mesmo com a forma $\mathrm{eu}$, o enunciado científico não será nunca a apresentação de um eu singular e sua lógica não é a da constituição de subjetividade, mas a da pretensão de objetividade. (AMORIM, 2004, p. 103).

Nesse trecho é possível compreender com clareza a situação comunicativa em que o artigo científico se instaura e a finalidade, ainda que ilusória, de se alcançar nele uma objetividade. Assim, não se pode negar que a sua construção deve atender a padrões normatizadores de escrita que promovam em certa medida o alcance desse ideal. Assim, é coerente e justificável que a escrita desse gênero se dê dentro de uma perspectiva de 
tentativa constante de apagamento do sujeito, a fim de que se sobressaia o objeto e não o sujeito.

\section{Diálogo entre os dois gêneros}

Apesar de serem dois gêneros produzidos em contextos sociais distintos, é possível estabelecer um diálogo entre eles, em vista das condições de produção que se coincidem com relação ao fato de ambas se darem em contexto social que permite pouca flexibilidade. Quando se analisa os gêneros, percebe-se muitas semelhanças no que diz respeito a regras e a tentativas de apagamento do sujeito.

No caso da redação do Enem, há o tamanho do texto (máximo de trinta linhas); a proibição de identificação do autor; a exigência de uso de repertório sociocultural legitimado pelas áreas de conhecimento; a obrigatoriedade de elaboração de uma proposta de intervenção; a estrutura do texto em ao menos três partes; a exigência de uso da norma padrão da língua portuguesa

Em comparação, quando se observa o artigo científico, temse o limite máximo de em média quinze páginas (a depender da revista de publicação ou do professor/instituição universitária); a proibição de identificação do autor; o uso de citações; a obrigatoriedade de elaboração de um resumo; a formatação específica segundo normas ABNT ou da própria editora/instituição; a exigência de uso da norma padrão da língua portuguesa.

Essas configurações próprias de cada um dos gêneros, tornam-nos extremamente padronizados, o que faz com que, ao examinarmos redações do Enem produzidas por candidatos os mais diversos, seja possível encontrarmos uma homogeneidade. Do mesmo modo, ao selecionarmos alguns artigos científicos, publicados ou não, também conseguimos encontrar neles homogeneidade. Isso é um dos elementos indicadores de que um gênero se constitui ali, visto que o contexto enunciativo social muitas vezes necessita estabelecer padronizações e tentativas de controle da escrita, haja vista a pluralidade de indivíduos carregados e repletos de ideologias que exercem tal atividade de linguagem. 


\section{Exemplos de engessamento}

O que segue são dados de uma coletânea de vinte e oito redações de participantes do ENEM 2020. Nos trechos abaixo é possível verificar como alguns dos participantes elaboraram a conclusão do texto.

\section{FIGURA 1 - Trechos das redações}

\section{Exemplo 1:}

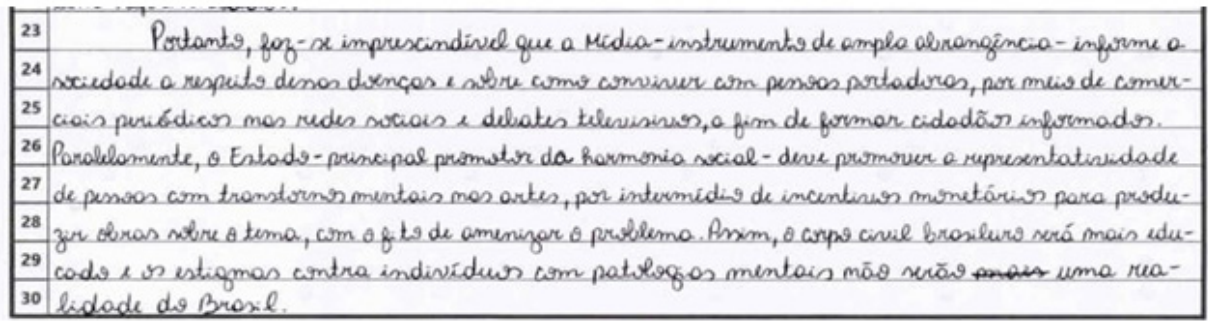

\section{Exemplo 2:}

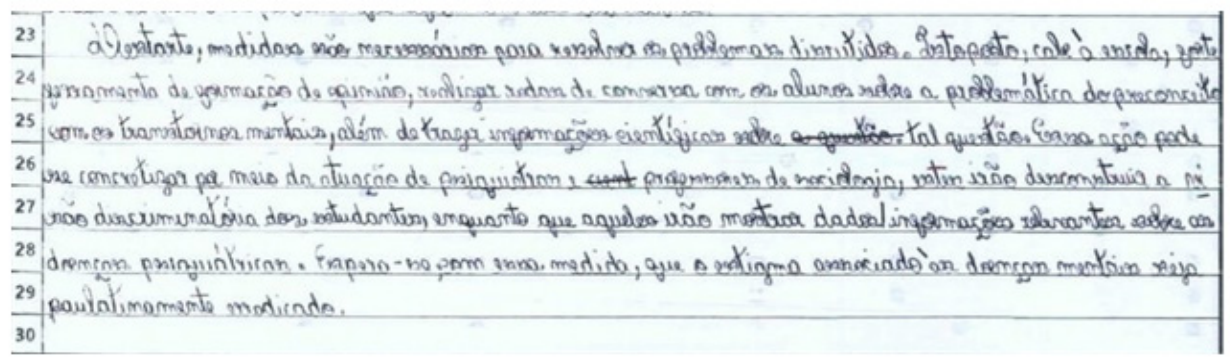

\section{Exemplo 3:}

\begin{tabular}{|c|c|}
\hline 23 & a tram to \\
\hline 24 & e governamental para combati-les. Diante disso, o Ministerio de saride dave \\
\hline 25 . & to de andimentes priquiátricos pillicos. \\
\hline 26 & ineito. love \\
\hline 27 & cia de gualid \\
\hline 28 & $x$ \\
\hline 29 & tifcenon \\
\hline & atc le \\
\hline
\end{tabular}

O engessamento de determinados gêneros discursivos reduz, mas não é capaz de eliminar as marcas deixadas pelo sujeito 


\section{Exemplo 4:}

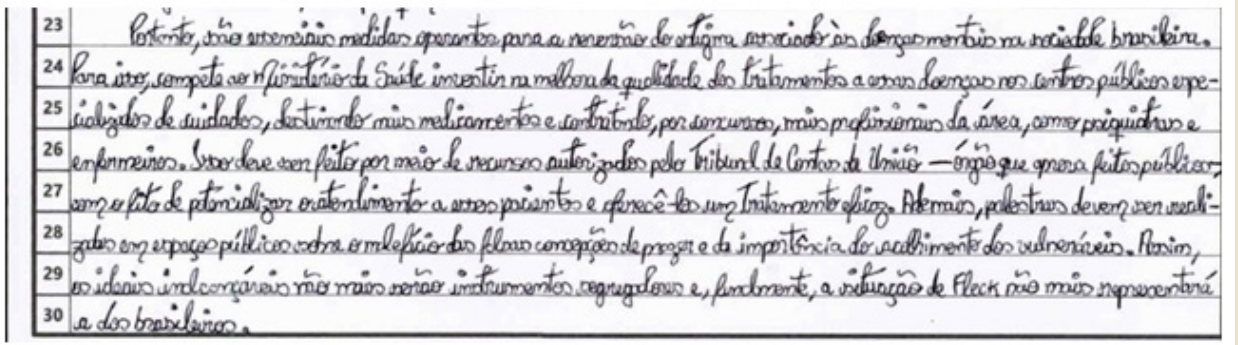

Fonte: Instituto Nacional de Estudos e Pesquisas Educacionais Anísio Teixeira (Inep), 2020.

Pode-se perceber nos exemplos e em todo o corpus analisado mais que um padrão estrutural (em que se observa até mesmo um número de linhas utilizadas para conclusão idêntico), mas também um padrão composicional de determinadas ocorrências lexicais, como "portanto", "por meio", "medidas", “assim”, "a fim de", "Ministério da Saúde”, o que evidencia, mais uma vez, que, embora haja uma variação textual, esta é pouco comprometedora. Percebe-se também uma organização das ideias que contribui para a apresentação sequencial dos cinco elementos exigidos pelo Enem acerca da configuração da proposta de intervenção, sendo eles: o agente, a ação, o meio/modo, a finalidade e o detalhamento de um dos elementos anteriores. Assim, o que se nota são as pequenas variações que garantem vida ao gênero e relativizam sua estabilidade, tal como compreendido por Bakhtin.

Abaixo seguem exemplos de resumos extraídos de artigos científicos de diferentes áreas publicados em revistas brasileiras: 


\section{Exemplo 1 Resumo}

O Brasil experimenta uma transição demográfica marcada por desigualdades regionais. É possível supor que aspectos relacionados à pobreza, desenvolvimento e desigualdade possam reverter os efeitos de associação dos indicadores da transição demográfica, tipificando um fenômeno conhecido como Paradoxo de Simpson. O objetivo foi analisar o efeito da desigualdade, pobreza e desenvolvimento social na dinâmica populacional brasileira, verificando a ocorrência do paradoxo de Simpson na transição demográfica. Foram utilizados dados populacionais oriundos dos Censos Demográficos brasileiros de 1991 a 2010, segundo idade e unidades da federação. Foi avaliada a correlação entre os indicadores demográficos, estratificando das unidades da federação em grupos de acordo com os indicadores sociais. Há um avanço das unidades federativas (UF) com relação aos indicadores sociais. A transição vem ocorrendo em todas as UF, com persistência da distância entre elas, mesmo que com redução ao longo dos anos. Observou-se o paradoxo de Simpson quando a análise foi realizada segundo ano censitário e indicador social, principalmente para o ano de 1991. O principal desafio é compreender como a dinâmica demográfica brasileira pode ser analisada e compreender de que forma os fatores contextuais alteram seu ritmo, quantum e padrão.

\section{Palavras-chave:}

Demografia; Transição demográfica; Pobreza; Iniquidade; Dessenvolvimente

\section{Exemplo 2}

\section{Resumo}

O objetivo foi analisar, em perspectiva comparada, estratégias e ações políticas adotadas em resposta à pandemia de COVID-19 na Alemanha e na Espanha em 2020. Baseando-se no institucionalismo histórico, o foco foi a institucionalidade da atuação governamental em cinco dimensões de atuação. Os resultados evidenciaram diferentes capacidades estatais na coordenação, implementacão e efetividade de estratégias. Pontos fortes da gestão e governança da crise estão relacionados ao reconhecimento da sua gravidade e capacidade de negociação; capacidade de produção nacional de insumos e equipamentos; e amplo direcionamento de recursos fiscais e financeiros do governo central para as áreas sanitária, social e econômica. Esses aspectos variaram entre os casos, atuando como diferencial relevante na resposta governamental. Outros diferenciais foram: estrutura do sistema de saúde; disponibilidade de trabalhadores; e sistema nacional de ciência e tecnologia, destacando a importância de investimentos de médio e longo prazo.

\section{Palavras-chave:}

Infecções por coronavírus; Política pública; Sistemas de saúde; Governança; Efeitos contextuais das desigualdades em saúde

\section{Exemplo 3}

\section{Resumo}

Em um contexto de recorrência de desastres, a naturalização ou rebaixamento destes à tragédia invisibiliza as dinâmicas e os processos envolvidos na afetação das comunidades e grupos populacionais mais vulneráveis a óbito e adoecimentos, como os idosos. Objetiva-se neste artigo descrever e analisar o contexto socioeconômico, ambiental e de saúde da afetação de idosos em quatro municípios dos estados de Santa Catarina e Rio de Janeiro. Para isto, realizou-se pesquisa documental, levantamento de dados abertos sociodemográficos, ambientais, econômicos e de saúde destas localidades e grupo populacional. Integraram-se as análises descritivas, de série temporal interrompida e documental. Dentre os resultados, observou-se nos documentos e dados levantados carência de previsão de ações preventivas ou mitigatórias voltadas a grupos prioritários. Para alguns grupos de causas, houve mudanças significativas no comportamento das internações hospitalares de idosos no período estudado. Conclui-se que o aprendizado institucional pautado na construção coletiva precisa ocorrer para corroborar com o rompimento do ciclo de repetição de desastres.

Palavras-chave:

Desastres naturais; Idoso; Internação hospitalar; Aspectos socioeconômicos 


\section{Exemplo 4}

Palavras-chave: Escrita, Autoria, Reconstrução de sentidos.

\section{Resumo}

Este artigo objetiva apresentar um exercício de escrita mediada por uma perspectiva dialógica da linguagem. Para isso, valemo-nos de um trabalho pautado na paráfrase e na reconstrução de sentidos, a partir da reescrita, empreendida por um acadêmico de Letras, de manchetes jornalísticas de caráter racial, fundadas desde uma visão preconceituosa e excludente. A ideia desenvolvida girou em torno da ressignificação de sentidos, tomando como direção escolhas e posicionamentos próprios do produtor do texto, num encaminhamento autoral de escrita. A perspectiva teórica baseou-se nas categorias conceituais bakhtinianas, tanto no tocante à análise das manchetes, quanto no que diz respeito às análises metadiscursivas empreendidas pelo autor das reescritas.

Fonte: Scielo Brasil e Cadernos CESPUC de Pesquisa.

Nos exemplos acima, é possível verificarmos uma homogeneidade no que se refere à forma e também ao conteúdo temático. Observa-se uma padronização nas escolhas lexicais formuladoras, tais como "objetiva", "este artigo". É possível identificar nos quatro exemplos e em todo o corpus analisado a regularidade na forma de construção do resumo. Isso se dá, pois o propósito comunicativo assumido é o mesmo em todos eles. Isso é o que o configura enquanto gênero. Há uma padronização no que se refere ao tamanho do texto, respeitando um número médio de palavras, no uso da terceira pessoa, que instaura uma perspectiva de distanciamento do sujeito escrevente e valoração do objeto sobre o qual se enuncia. Além disso, as ideias progridem em sentido comum, iniciando por uma abordagem temática contextualizadora e justificadora da relevância da discussão proposta pelo artigo científico, seguida de objetivos/ metodologia/ esboço das conclusões. Essa regularidade é importante, pois materializa o gênero em sua função social. No entanto, a relativa estabilidade do gênero do discurso não o torna imune à passagem do tempo, a acontecimentos históricos e sociais que o fizeram nascer, o configuraram e continuam a participar de seu processo evolutivo. 


\section{Sujeito "vivo"}

Por mais engessados e cristalizados que determinados gêneros possam ser, o sujeito se revela a todo momento. Ainda que os textos analisados em cada um dos gêneros possuam estabilidades e muitos pontos em comum, há sempre marcas do sujeito que os diferenciam. Quanto mais o sujeito domina o gênero discursivo, mais permissões ele adquire para ser livre respeitando as especificidades do gênero.

De acordo com Amorim (2004, p. 102), “quando alguém se enuncia como locutor, ele se mostra e fala também, necessariamente, de si próprio, pois é precisamente ao dirigir a palavra a alguém que se exprime e reafirma a subjetividade." Nesse sentido, é necessário reafirmar que o sujeito em sua subjetividade aparece em todo e qualquer gênero textual, na medida em que ele, enquanto indivíduo único e atravessado por suas experiências sociais e históricas, está sempre implicado em seu enunciado. Assim, por mais que as suas marcas sejam menos facilmente reconhecíveis, devido a tentativas de ofuscamento, ele se mantém o tempo todo presente.

Nessa perspectiva, pode-se identificar o sujeito "vivo" em muitos momentos dos gêneros em análise. Observemos as conclusões de redações do Enem e os resumos de artigos científicos. Há presente neles marcas de atitude responsiva e indiciadores de posições sociais e históricas ocupadas pelos escreventes dos textos produzidos. Em toda a seleção que o estudante candidato ao Enem faz dos elementos que farão parte da sua elaboração de proposta interventiva revela-se por quais percursos e contextos esse sujeito foi carregado ao longo da sua experiência social. A concepção que cada um deles faz de quais alternativas seriam mais legítimas para solucionar uma situação problema é refletida no texto, por mais que isso se dê de forma inconsciente. O mesmo se verifica nas construções dos resumos, em que o sujeito busca se ofuscar em meio ao uso da terceira pessoa, mas se revela a todo momento na atividade da linguagem. No último resumo, verificase adjetivações reveladoras de um sujeito ideológico, quando se opta por classificar as manchetes jornalísticas analisadas como preconceituosas. Já no terceiro resumo, o uso do termo "tragédias" para se referir ao fato e, posteriormente, o uso de "naturalização" ou "rebaixamento" para classificar a forma como estas são vistas é inegavelmente uma evidência de um sujeito 
encarnado no ato da linguagem que enuncia e se mostra com todas as suas ideologias que o engendram. Esses são apenas alguns exemplos que nos permitem verificar a primeira tese proposta neste artigo.

\section{O domínio dos gêneros}

A partir dos anos 2000, foi possível assistir a um extraordinário crescimento de oferta de cursos de redação do Enem que prometem o alcance da almejada nota mil. O mesmo cenário se verifica acerca da escrita de artigo científico, que aparece didatizada em diversos cursos online ofertados por profissionais da área ou até mesmo de outras áreas. A promessa é, analogamente ao alcance da nota mil do Enem, a de possibilidade de publicação em revistas renomadas, inclusive internacionais. A alta procura por essas aulas ressalta um despreparo e uma insegurança dos estudantes frente aos gêneros em estudo. Por meio de fórmulas rápidas para melhorar a escrita e ideias soltas de repertório sociocultural, muitos cursos simplificam e reduzem o gênero redação do Enem a um molde textual. No entanto, a cada ano o número de participantes que atingem a nota máxima no exame reduz. Esse acontecimento revela um problema: o desconhecimento do gênero redação do Enem.

De modo similar, na prática científica de pesquisa e respectiva publicação, verifica-se cenário semelhante, identificado por meio de um número crescente de publicações destinadas ao ensino da escrita de pesquisa, que didatizam o gênero artigo científico. Há, também, a crescente oferta de cursos de escrita de artigo científico na internet com alta procura, muitas vezes ministrados por profissionais cuja formação não é da área da linguagem e baseados em fórmulas rápidas para melhorar a escrita e produzir artigos aceitos nacional e internacionalmente. É importante salientar que a capacidade em operar/trabalhar/escolher um gênero está diretamente ligada ao domínio que temos em relação a ele. Isto é, quanto maior for essa familiaridade, mais facilidade teremos em empregá-lo de forma adequada, nas situações comunicativas em que estivermos inseridos. Para Bakhtin, é a própria (com)vivência nas situações comunicativas e o contato com os diferentes gêneros do discurso que exercitam a competência linguística 
de quem os produz. É a competência linguística dos interlocutores que auxilia na aceitação, ou não aceitação, nas diversas práticas sociais. Quanto mais experiente o sujeito, maior será a sua competência em reconhecer um gênero e a estrutura que ele compõe.

Logo, restringir os textos, nas práticas pedagógicas, apenas pelo modo como se organizam é um risco de limitá-los a fórmulas ou esquemas que os descaracterizem de seus propósitos comunicativos. Devemos, então, pensar o quanto uma mudança de concepção de ensino e aprendizagem se faz necessária. Ainda mais, em um momento histórico como o que vivemos, em que mudanças econômicas e políticas trazidas a reboque do fenômeno da "globalização" trazem a todo instante profundas consequências culturais e diretamente, novas práticas sociais.

\section{Considerações finais}

A nossa vida é controlada. Sempre haverá tentativa de controle em todas as formas de atividade humana. Assim, a linguagem, como a principal forma de atividade humana, evidencia, por meio dos gêneros discursivos, essa forma de organização social e histórica que nos atravessa.

No entanto, é preciso buscar compreender o funcionamento dos gêneros em nossa sociedade, no intuito de dar condições para que o escrevente, conhecendo as regras, mostre-se o mais livremente possível através da sua escrita. Desse modo, é importante pensar que o problema não está no gênero, mas no desconhecimento que se tem dele. Esse conhecimento é a maior ferramenta que se tem para o entendimento das organizações sociais. Conhecendo o gênero também é possível ser livre, entendendo que, do mesmo modo que este nasce em uma situação comunicativa específica e histórica, ele não está imune à passagem do tempo e às mudanças sociais; estas sim capazes de alterar as configurações dos gêneros existentes. 


\section{Referências}

AMORIM, Marília. Enunciado Científico e texto polifônico In: AMORIM, Marília . O pesquisador e seu outro: Bakhtin nas Ciências da Linguagem. São Paulo: Musa, 2004. p. 92-146.

AUTHIER-REVUZ, Jacqueline. Dizer ao outro no já-dito: interferências de alteridades - interlocutiva e interdiscursiva - no coração do dizer. Letras de Hoje, Porto Alegre, v. 46, n. 1, p. 6-20, jan./mar. 2011, Disponível em: https://revistaseletronicas.pucrs.br/ojs/index.php/fale/article/view/9215. Acesso em: 5 maio 2020.

AUTHIER-REVUZ, Jacqueline. Hetorogeneidade(s) enunciativa(s). Cadernos de Estudos Linguísticos, Campinas, n. 19, jul./dez. 1990. Disponível em: https://periodicos.sbu.unicamp.br/ojs/index.php/cel/ article/view/8636824. Acesso em: 5 maio 2020.

BAKHTIN, Mikhail Mikhailovich. Os gêneros do discurso. In: Estética da criação verbal. Organização, tradução, posfácio e notas de Paulo Bezerra. 4. ed. São Paulo: Martins Fontes, 2003, p. 261-306.

BRASIL. Guia do Participante: a redação do ENEM. 2016. Disponível em: $\quad<$ http://download.inep.gov.br/educacao_basica/enem/guia participante/2016/manual_de_redacao_do_enem_2016.pdf $>$. Acesso em: 8 set. 2021.

FAÏTA, Daniel. A noção de gênero discursivo em Bakhtin: uma mudança de paradigma. In: BRAIT, Beth (org.). Bakhtin, dialogismo e construção do sentido. 2. d. Campinas, SP: Editora da UNICAMP, 2001. p.149-168.

FIAD, Raquel Salek. A Escrita Na Universidade Revista da ABRALIN, v. Eletrônico, n. Especial, p. 357-369. $2^{\text {a }}$ parte 2011.

ORLANDI, Eni. Volatilidade da interpretação: política, imaginário e fantasia. Palestra na Abralin ao Vivo. Disponível em: https://www.youtube. com/watch?v=MjCsJxfiXtg. Acesso em 2 set. 2021. 
SCHNEUWLY, Bernard. Gêneros e tipos de discurso: considerações psicológicas e ontogenéticas. In: SCHNEUWLY, B.; DOLZ, J. (org.). Gêneros orais e escritos na escola. Tradução e organização Roxane Rojo e Glaís S. Cordeiro. Campinas: Mercado de Letras, 2004, p. 21-39.

VOLÓCHINOV, Valentin Nikolaevich. (Círculo de Bakhtin). Marxismo e Filosofia da Linguagem: problemas fundamentais do método sociológico. Tradução, notas e glossário de Sheila Grillo e Ekaterina Vólkova Américo. São Paulo: Editora 34, 2017.

ZAVALA, Virgínia. Quem está dizendo isso?: letramento acadêmico, identidade e poder na educação superior. In: VÓVIO, C.; SITO, 1..; GRANDE, P. (org.). Letramentos: rupturas, deslocamentos e repercussões de pesquisas em linguística aplicada. Campinas, SP: Mercado de Letras, 2010. 